roundings. He does not show the irascibility which patients with his disease are said to have, nor does he soil himself or make a general nuisance of himself or his attendants. Memory is very poor. Reflexes are diminished, plantar irritation provokes dorsal flexion. He does not seem to be able to smell.

Dr: Alfred Gordon stated that the case was quite typical of Huntington's chorea. The only peculiarity about it was the involvement of the upper part of the face. In the typical Huntington's chorea only the lower half of the face is affected. The eye globes are usually not involved. In this case they are. An interesting point in the history of the case is the headache, which goes hand in hand with what we know of the pathological anatomy. This is supposed to be a meningoencephalitis.

\title{
CHICAGO NEUROLOGICAL SOCIETY
}

October 22, I908

\author{
The President, Dr. Richard Dewey, in the Chair \\ CLINICAL OBSERVATIONS OF PSYCHOSES PRESENTING \\ THE EDDY CULT AS A COMPLICATION
}

By Richard Dewey, M.D.

This was a study of 8 cases in which the psychoses developed in connection with espousal of Eddyism. They were selected as typical from a large number seen during the years since Christian Science, so-called, became a method of treatment.

The Eddyism was, of course, regarded as occasion rather than cause: of the mental disease, since insanity in all cases has a constitutional background of instability.

The paper was intended as a slight contribution to the question whether there was anything characteristic, $i$. $e$, whether the psychopathic reactions observed showed a particular form.

The 8 cases consisted of -3 of paranoia, 4 of manic-depressive insanity and I of psychasthenia. There was one of recovery (manic-depressive) and I of virtual recovery (psychasthenia), as the patient again returned to her accustomed work of teaching; the other cases all became chronic with indications of an incurable state. One of the marked psychopathic phases was panophobia for the pharmacopeia (in connection with these phobias it is to be mentioned that 3 patients showed marked delusions of poisoning). This was present in 6 of the 8 cases-a natural outgrowth of the Eddy doctrine. Two of the cases showed a disposition to religious. fasting; 3 manifested folie du doute; 3 had obsessions of exil spirits; 4 showed erotism; suiçide and attempt at self injury were present in 5 cases.

The group of the 3 paranoiacs all manifested continuous and unwavering adherence to Eddyite ideas with an exalted frame of mind. These patients were in good physical condition.

In the manic-depressive group there was I recovery with abandonment of all Eddyite idcas. The three that became chronic cases showed intense depression and a sense of failure and disappointment which might be attributable to the peculiar contradictory and confusing method of thought 
and the effort to ignore or annihilate physical and mental ills by denying and refusing to recognize. All of these cases made attempts at suicide, or self injury, in the most persistent manner, and there was noticeable, in 2 of them, a delusion of self-condemnation and unworthiness arising from a belief that they did not possess the spiritual worth and force requisite to overcome, by. faith, the physical ills, or to practice "healing" as they had planned.

The patient, suffering from psychasthenia, was intensely depressed by fear of demoniacal possession, having been told by those who were treating her that if she gave way to unbelief evil spirits would wholly possess her.

It is easy to understand how ignoring a persistent pain, or denying the existence of a tumor, may result in mental strain. The disappointment of an ecstatic expectation of marvels may also plunge an unstable mind into corresponding despair.

The whole result of so-called Christian Science has been beneficial in a way never anticipated by convincing masses of people of the reality of a force for physical good residing in the mind, but victims of incurable organic disease or neurotic defect who endeavor to think or "will" disease out of existence, if defective of brain, tend to fall into deeper disease and disorder.

Dr. Sydney Kuh had seen a number of cases of melancholia, using the term merely as indicating a group of symptoms and not a type of disease, in which Christian Science seemed to have a decidedly bad effect and he could readily see how this could be brought about. One case in which this influence was particularly clear is a woman whom he had seen in three or four attacks of melancholia. He saw this woman the first time towards what was very probably the end of the attack, and she recovered in a very short time after he took charge. The recovery from the second attack was not so prompt as from the first, and the friends became dissatisfied. He was dismissed and a healer was employed, with the result that the patient very rapidly became worse. The religious ideas which she was supposed to absorb were utilized by her in the way in which melancholia patients will work up religious ideas. She began to realize fully what a horrible sinner she had been all her life, and the influence of the treatment was very disastrous, and in a very short time the family realized they were doing harm, and again changed from Christian Science to treatment by a physician.

It was a particularly striking case because the patient had been so much better before Christian Science had been employed, and because after the Christian Science healer had been dismissed there was again fairly rapid improvement in the case. Dr. Kuh did not believe that Christian Science does harm to the patient in all cases of depressive types of insanity, but believed that in melancholia it is very often decidedly harmful.

\section{MULTIPLE SCLEROSIS OR HYSTERIA?}

\section{By William Healy, M.D.}

Mr. X, age 38 , single, painter and paperhanger, born in Germany. Father died of pneumonia, mother of heart trouble, three brothers died, ages four or five; one sister died at thirty, jaundiced; one sister aged thirty-six, well and strong, but has suffered from gall-stones. 